\title{
The Potato Transcriptional Co-activator StMBF1 Is Up-regulated in Response to Oxidative Stress and Interacts with the TATA-box Binding Protein
}

\author{
Débora Pamela Arce', Claudia Tonón¹, María Eugenia Zanetti ${ }^{*}$, Andrea Verónica Godoy ${ }^{1}$, \\ Susumu Hirose ${ }^{2}$ and Claudia Anahí Casalonguée ${ }^{1,3, *}$ \\ ${ }^{1}$ Instituto de Investigaciones Biológicas, FCEyN, UNMDP \\ ${ }^{2}$ Department of Developmental Genetics, National Institute of Genetics and Department of Genetics, \\ Graduate University for Advanced Studies, Yata 1111, Mishima, 411-8540 Japan \\ ${ }^{3}$ Departamento de Biología, FCEyN-UNMDP, CP 7600, Mar del Plata, Buenos Aires, Argentina
}

Received 11 November 2005, Accepted 23 January 2006

\begin{abstract}
To gain a better understanding on the function of the potato Solanum tuberosum Multiprotein Bridging Factor 1 protein (StMBF1) its interaction with the TATA box binding protein (TBP) was demonstrated. In addition we reported that $S t M B F 1$ rescues the yeast mbf1 mutant phenotype, indicating its role as a plant co-activator. These data reinforce the hypothesis that MBF1 function is also conserved among non closely related plant species. In addition, measurement of StMBF1 protein level by Western blot using anti-StMBF1 antibodies indicated that the protein level increased upon $\mathrm{H}_{2} \mathrm{O}_{2}$ and heat shock treatments. However, the potato $\beta-1,3$-glucanase protein level was not changed under the same experimental conditions. These data indicate that StMBF1 participates in the cell stress response against oxidative stress allowing us to suggest that MBF1 genes from different plant groups may share similar functions.
\end{abstract}

Keywords: MBF1, Solanum tuberosum, Stress, Transcriptional co-activator

\section{Introduction}

The expression of a gene is dictated, in part, by the integration of cellular and environmental signals that control the activity of transcription regulatory proteins. Transcriptional regulation plays a major role in the expression of the genomic information during complex biological processes. The presence of the TATA-box binding protein (TBP) at the TATA box is a pivotal intermediary step in transcriptional activation of protein coding genes. When this step occurs, a number of other transcription factors form a complex that recruits the RNA polymerase II, allowing transcription to proceed. The accessibility and binding of TBP to the promoter can be regulated by different regulatory proteins (Pugh, 2000).

A category of eukaryotic proteins named co-activators, which enhance transcription by interacting with both general and gene-specific transcription factors, has been identified and isolated from fungi, metazoan and plants (Takemaru et al., 1997; Zhu et al., 2000; Tsuda et al., 2004). Multiprotein Bridging Factor 1 (MBF1) was originally purified from extracts of the silkworm Bombyx mori and identified as a transcriptional co-activator that interacts with the TBP and the Drosophila melanogaster nuclear receptor FTZ-F1 (Li et al., 1994). Yeast and mammal MBF1 proteins bind to different transcription factors of the basic leucine zipper (bZIP) family, including yeast GCN4 and human AP-1 (Takemaru et al., 1998; Kabe et al., 1999; Brendel et al., 2002; Busk et al., 2003). Jindra et al. (2004) reported that MBF1 is a positive modulator of AP-1. MBF1 prevents an oxidative modification (S-cystenyl cystenylation) of a critical cysteine and stimulates AP-1 binding to DNA, preserving the redox-sensitive AP-1 activity via a direct interaction with the basic region of Drosophila D-Jun.

Godoy et al. (2001) isolated and characterized a potato cDNA clone, StMBF1, which encodes a protein with high

\footnotetext{
*To whom correspondence should be addresse

E-mail: casalong@mdp.edu.ar tuberosum MBF1; TBP, TATA-box binding protein ter for Plant Cell Biology. University of California
}

Abbreviations: 3-AT, 3-aminotriazole; GST, glutathione S-trans-

${ }^{\#}$ Present address: Department of Botany and Plant Sciences and Cen- 
sequence homology to the human, yeast and B. mori MBF1 genes. StMBF1 also shows a high degree of conservation with other MBF1 sequences of plant species. However, most of them have not been yet functionally characterized (Tsuda and Yamazaki, 2004). Tsuda et al. (2004) demonstrated that all three Arabidopsis MBF1 genes can complement MBF1 deficiency in yeast. Tsuda and Yamazaki (2004) identified two plant groups (I and II) of MBF1 genes by comparison of deduced amino acid sequences of three AtMBF1 subtypes with those of other MBF1s. The extent of amino acid sequence identity indicated that AtMBF1 a (At2g42680) and AtMBF1 b (At3g58680) belong to the same group I, as StMBF1. However, AtMBF1 c (At3g24500) resides in the group II. The steady-state level of transcripts encoding AtMBF1 c is elevated in Arabidopsis in response to different stress conditions (Tsuda and Yamazaki, 2004). Contrary, AtMBF1 a and AtMBF1 b are developmentally regulated (Tsuda et al., 2004). In the case of StMBF1, its expression is induced by wounding and Fusarium eumartii attack in a non photosynthetic organ, such as potato tubers. In addition, Zanetti et al. (2003) reported that StMBF1 is phosphorylated and the phosphorylation status is positively regulated after treatment of potato cells with Phytophthora infestans cell wall elicitors. The study of potato defense mechanisms against different environmental stresses is an important subject in the agronomical field; however, the role of StMBF1 as a potato transcriptional co-activator and its relative contribution to biotic and abiotic stress tolerance remains unknown.

Here, we report that $S t \mathrm{MBF} 1$ protein is induced in potato cell suspensions growing under oxidative stress conditions. In addition, StMBF1 interacts with the potato TBP protein and it is able to complement mutant yeast lacking the $y \mathrm{MBF} 1$ gene. In plants, the functional conservation of MBF1 as transcriptional co-activators can be deduced from these observations. Finally, MBF1 proteins could, therefore, be good candidates to perform a protective role during oxidative stress.

\section{Materials and Methods}

Cell suspension cultures and stress treatments. Cell suspension cultures of Solanum tuberosum L cv Spunta, established from friable calli, were maintained in liquid MS medium (Murashige and Skoog, 1962) supplemented with 3\% sucrose and phytohormones: 2, 4-D $\left(2 \mathrm{mg} \mathrm{ml}^{-1}\right)$ and NAA $\left(2 \mathrm{mg} \mathrm{ml}^{-1}\right)$. Cell suspension cultures were grown in $50 \mathrm{ml}$ of MS medium at $25^{\circ} \mathrm{C}$ in the dark, with shaking at $125 \mathrm{rpm}$. These cultures were transferred into fresh medium at 7-d intervals. For experiments, aliquots of $10 \mathrm{ml}$ of cell suspensions in the log growth phase were treated with $20 \mathrm{mM}$ $\mathrm{H}_{2} \mathrm{O}_{2}$; controls were treated with sterile distilled water. At different time points, cells were collected by vacuum filtration, washed with distilled water and stored at $-80^{\circ} \mathrm{C}$. The cell viability was determined by Evan's blue (Merck) staining under light microscope. Five hundred $\mu \mathrm{l}$ of $1 \%$ Evan's blue solution were added to $1 \mathrm{ml}$ of cell suspension. After $20 \mathrm{~min}$, the mixture was centrifuged at $750 \times \mathrm{g}$ for $2 \mathrm{~min}$ and washed with MS medium. Approximately 400 cells were counted per microscopy field.

Preparation of protein extracts. Potato cells were homogenized in a mortar with liquid nitrogen and suspended in one volume of cold extraction buffer: $60 \mathrm{mM}$ Tris- $\mathrm{HCl}(\mathrm{pH} 6.8), 0.1 \%$ bromophenol blue, $25 \%$ glycerol, $2 \%$ SDS and 5\% mercaptoethanol. The cell lysates were incubated for $30 \mathrm{~min}$ at $4^{\circ} \mathrm{C}$ and centrifuged at 12,070 $\times g$ for $30 \mathrm{~min}$. The supernatants were transferred into clean tubes and stored at $-20^{\circ} \mathrm{C}$.

Western blot assays. For Western blot assays, total proteins from potato cells (50 mg fresh weight) were extracted in sample buffer. Protein samples were boiled for $5 \mathrm{~min}$ and running on $12 \%$ SDSPAGE. The proteins were transferred to a nitrocellulose membrane (BioRad). Bound StMBF1 and potato $\beta$-1,3-glucanase were detected by a Western blot analysis using the anti-StMBF1 antibody at a dilution of $1: 3,000$ (Zanetti et al., 2003) and the anti- $\beta$-1,3-glucanase at a dilution of $1: 7,000$ (Tonón et al., 2002), respectively. The blots were allowed to react with goat antirabbit antibody $(1: 10,000)$ labeled with alkaline phosphatase (Sigma) and revealed with BCIP/ NBT according to procedures recommended by the manufacturer.

Preparation of recombinant proteins. To produce Schistosoma japonicum GST-TBP fusion protein in Escherichia coli, the ORF of Solanum tuberosum TBP was amplified by RT-PCR using potato RNA as template. The following primer combinations were used: StTBPup (5'-CTCTGGATCCATGGCAGATCAGGGATTAGAG-3') and StTBPlw (5'-CTCTCTCGAGTGCTCCACAGTCCATCAAAT C-3'). The PCR primers were designed to incorporate a BamHI site in the 5' end and an EcoRI site at the 3' end of the PCR product. The amplified DNA fragment was cloned into the BamHI and EcoRI sites of pGEX-4T-3 (Amersham Pharmacia Biotech). The resulting construct was verified by sequencing. E. coli BL21 (DE3) cells bearing the pGEX-TBP construct were grown in $2 \mathrm{X}$ YT medium (16 $\mathrm{g} \mathrm{l}^{-1}$ tryptone, $10 \mathrm{~g} \mathrm{l}^{-1}$ yeast extract, and $5 \mathrm{~g} \mathrm{l}^{-1} \mathrm{NaCl}$ ) with $2 \%$ glucose and $0.1 \mathrm{mg} \mathrm{ml}^{-1}$ ampicillin overnight at $37^{\circ} \mathrm{C}$. The culture was diluted 100 times in fresh medium and the cells were grown under the same conditions until an $\mathrm{Abs}_{600}=0.8$ was reached. Expression of the fusion protein was induced by the addition of 0.1 $\mathrm{mM}$ isopropyl-1-thio- $\beta$-D galactopyranoside (IPTG) for $4 \mathrm{~h}$ at $25^{\circ} \mathrm{C}$. The cells were harvested by centrifugation at $3,000 \times g$ for 10 min and suspended in $0.5 \mathrm{vol}$ of PBS $(25 \mathrm{mM}$ sodium phosphate buffer $\mathrm{pH} 7.2,150 \mathrm{mM} \mathrm{NaCl}$ ) containing $5 \mathrm{mM}$ EDTA, $1 \mathrm{mM}$ PMSF, $5 \mathrm{mg} \mathrm{ml}^{-1}$ leupeptin, $20 \mathrm{mg} \mathrm{ml}^{-1}$ pepstatin and $1 \mathrm{mg} \mathrm{ml}^{-1}$ lysozyme. After one freeze/thaw cycle and sonication, the lysates were clarified by centrifugation at $10,000 \times g$ for $20 \mathrm{~min}$ at $4^{\circ} \mathrm{C}$. GST and GST-TBP proteins were purified by affinity chromatography according to the manufacturer's instructions (Amersham Biosciences).

$S t \mathrm{MBF} 1$ was also expressed as GST fusion protein in $E$. coli (Zanetti et al., 2003). After affinity purification, StMBF1 was released from the GST moiety by thrombin treatment according to the manufacturer's instructions (Amersham Biosciences).

Antibody production. Polyclonal antibodies against GST-TBP were raised in rabbits according to Harlow and Lane (1988). The titer and specificity of the antiserum were tested against $E$. colipurified GST-TBP by Western blot analysis. 
GST pull-down assay. Bacterially expressed GST or GST-TBP were incubated with $5 \mu \mathrm{l}$ (packed volume) of GSH-Agarose 4B (Molecular Probes, Oregon, USA) for $1 \mathrm{~h}$ at $4^{\circ} \mathrm{C}$. After washing, $1 \mu \mathrm{g}$ of purified StMBF1 was added in $500 \mu \mathrm{l}$ of protein-binding buffer (PBB) (20 mM HEPES-KOH pH 7.5, 20\% glycerol, $0.1 \%$ Nonidet P-40, $0.5 \mathrm{mM}$ EDTA, $50 \mathrm{mM} \mathrm{KCl}, 10 \mathrm{mM} \mathrm{MgCl} 2,1 \mathrm{mM}$ DTT and $1 \mathrm{mM}$ PMSF). The mixture was rolled for $2 \mathrm{~h}$ at $4^{\circ} \mathrm{C}$. The beads were washed twice with $500 \mu \mathrm{l}$ of PBB and suspended in 10 $\mu 1$ of SDS-PAGE sample buffer. The bound proteins were eluted by boiling, loaded onto a 15\% SDS-polyacrylamide gel, and blotted to a nitrocellulose membrane (BioRad, Hercules, USA). Bound StMBF1 was detected by a Western blot using the anti-StMBF1 antibody (Zanetti et al., 2003).

Co-immunoprecipitation assay. Approximately $40 \mu \mathrm{l}$ of Protein A Sepharose CL-4B (Sigma) was incubated for $2 \mathrm{~h}$ at $4^{\circ} \mathrm{C}$ with the anti-StMBF1 antibody at a dilution of $1: 25$. Approximately equivalent molar amounts of purified StMBF1 and GST-TBP proteins were preincubated in PBS overnight at $4^{\circ} \mathrm{C}$ and added to the antibodyloaded beads. After $2 \mathrm{~h}$ of incubation at $4^{\circ} \mathrm{C}$, the beads were washed with buffer B (10 mM TRIS-HCl pH 7.4, 0.1\% SDS, 1\% Triton X$100,1 \%$ sodium deoxycolate, $1 \mathrm{mM}$ PMSF), and subsequently with $1 \times$ TBS buffer and a dilution of $1: 10$ of TBS buffer. Bound proteins were eluted with SDS sample buffer, boiled for $5 \mathrm{~min}$, resolved on $15 \%$ SDS-PAGE and analyzed by Western blots.

Yeast complementation assay. Wild-type strain KT130 and mutant strain $\triangle m b f 1, \mathrm{KT} 131$, were obtained from Dr Hirose's laboratory (Takemaru et al., 1998). The DNA fragment corresponding to StMBF1 open reading frame (ORF) was amplified by PCR using the following primers: 5'-CCAGGAATTCATGAGTGGAATATCG CAAGAC-3' and 5'-CCAGGGATCCTTTCTTTCCTCGAAGTTT CG-3'. Then, the DNA fragment was cloned into EcoRI and BamHI sites of pGBT9 vector (Clontech). pGBT9-StMBF1 and pGBT9 were introduced into yeast $\Delta m b f 1$ competent cells by lithium acetate procedure as described by the manufacturer (Clontech).

\section{Results and Discussion}

Previously, we have shown that StMBF1 interacts with HdZip protein Hahb4 increasing the affinity of these proteins for their DNA target sites (Zanetti et al., 2004). This raises the possibility that $S t \mathrm{MBF} 1$ can also interact with TBP in a conserved manner. In this work, we examined StMBF1 and potato TBP interaction. For this, both proteins were expressed in $E$. coli as translational fusions to GST. In order to reduce nonspecific binding, E. coli protein extracts containing the GST-TBP were used as described by Swaffield and Johnston (1996). Same amounts $(900 \mu \mathrm{g})$ of total protein extracts containing GST or GST-TBP were used in combination with purified StMBF1 in GST pull-down assays. Thereafter, Fig. 1 (upper panel) shows that equivalent amounts of GST and GST-TBP proteins were eluted from the GSH- Agarose. Western blot analysis of the affinity-purified proteincomplexes showed that a significant amount of StMBF1 protein was bound to GSH-Agarose when the GST-TBP

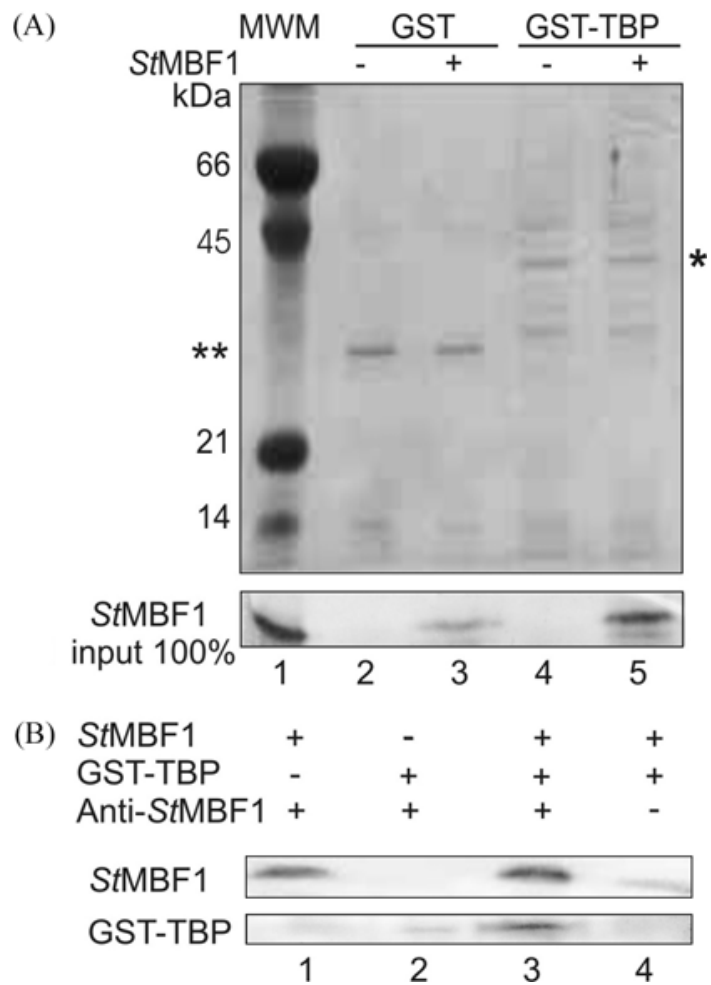

Fig. 1. In vitro protein-protein interaction. (A) GST pull-down assay for the interaction between StMBF1 and TBP. StMBF1 (1 $\mu \mathrm{g})$ was incubated with total protein extracts containing GST (lanes 2 and 3) or GST-TBP (lanes 4 and 5). The bound proteins were analyzed by $15 \%$ SDS-PAGE and detected by Coomassie blue staining (upper panel) or Western blot (lower panel) using anti-StMBF1 antibody. Lane 1 (upper panel): molecular weight markers. Lane 1 (lower panel): input StMBF1. GST-TBP (*), GST (**). (B) Co-immunoprecipitation assay. StMBF1 was incubated with various combinations of proteins and subjected to immunoprecipitation with anti-StMBF1 antibodies immobilized to Protein-A Sepharose. Immunoprecipitates were analyzed by Western blot using anti-StMBF1 (upper panel) or anti-GST-TBP (lower panel) antibodies.

protein was present (Fig. 1A, lower panel, lane 5). By contrast, only a faint band was observed when extracts containing GST were used (Fig.1A, lower panel, lane 3) and no band was detected when StMBF1 was omitted (Fig. 1A, lower panel, lanes 2 and 4). This result indicates that both proteins, StMBF1 and TBP, interact in vitro. Then, the StMBF1 and TBP interaction was confirmed by a coimmunoprecipitation assay. The protein complexes were analyzed by Western blots using both anti-StMBF1 and antiGST-TBP antibodies. GST-TBP was co-immunoprecipitated with $S t \mathrm{MBF} 1$, as evidenced by the detection of a prominent band of GST-TBP (Fig. 1B, lower panel, lane 3). A very faint band was detected in the absence of StMBF1, suggesting a weak cross-immunoreactivity between the TBP and the antiStMBF1 antibody (Fig. 1B, lower panel, lane 2). As control, Fig. 1B (upper panel) shows the presence or absence of 


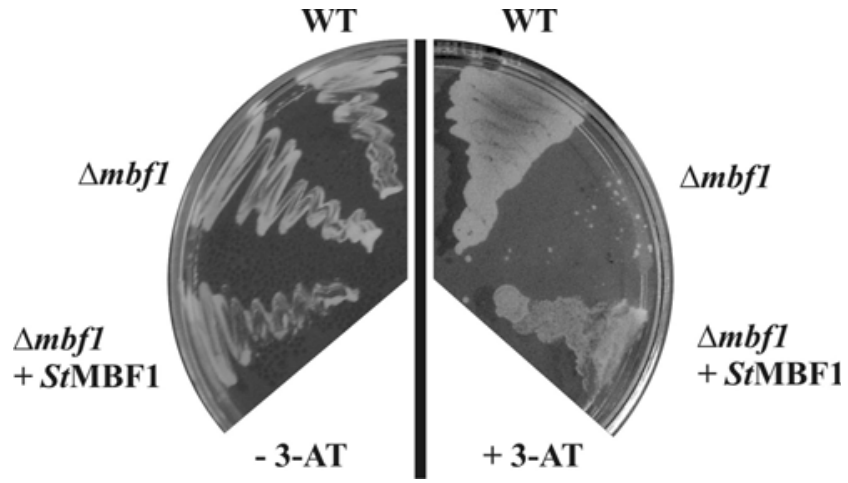

Fig. 2. Phenotype of the $\Delta m b f 1$ strain. Cells of the yeast wild type strain (WT, KT130) and the $\Delta m b f 1$ strain (KT131) were transformed with the empty vector (pGBT9); the $\Delta m b f 1$ strain was transformed with pGBT9-StMBF1 $(\Delta m b f 1+S t \mathrm{MBF} 1)$. All yeast strains were grown on plates in the presence $(+3-\mathrm{AT})$ or absence (-3-AT) of $50 \mathrm{mM}$ AT for 3 days at $30^{\circ} \mathrm{C}$.

StMBF1 in each reaction. All these results support the interaction between StMBF1 and TBP proteins indicating the presence of a common regulatory mechanism in two plant species, Arabidopsis thaliana and Solanum tuberosum which are not closely related to each other.

Takemaru et al. (1998) have described that $y \mathrm{MBF} 1$ mediates the GCN4-dependent transcriptional activation of the His3 gene by bridging between GCN4 and TBP. The yeast mutant lacking either MBF1 or GCN4 are viable, but sensitive to 3aminotriazole (3-AT), an inhibitor of the His3 gene product. More recently, Tsuda et al. (2004) have demonstrated that AtMBF1 proteins function as co-activators for GCN4dependent transcriptional activation in yeast. Here we tested the function of StMBF1 as a co-activator by complementation of the yeast mutant $\Delta m b f 1$ strain, KT131, with $S t \mathrm{MBF} 1$. The $\Delta m b f 1$ strain transformed with the empty vector, pGBT9, was sensitive to 3-AT (Fig. 3). Expression of StMBF1 cDNA (pGBT9-StMBF1) rescued the yeast $\Delta m b f 1$ mutant phenotype upon histidine starvation in the presence of 3-AT. All yeast strains used in this experiment showed essentially the same normal growth rate on histidine-free medium in the absence of 3-AT (Fig. 3). These results indicate that StMBF1 also acts as a co-activator for GCN4-dependent transcriptional activation in yeast cells. Based on these data, we concluded that StMBF1 is an evolutionarily conserved transcriptional co-activator that connects the TATA element-binding protein and a regulatory transcriptional factor as it has been demonstrated for MBF1 of other species (Li et al., 1994; Takemaru et al., 1998; Kabe et al., 1999 and Tsuda et al., 2004). Taking together this new finding and our previous results we suggest that StMBF1 may serve as a bridging molecule between TBP and Hd-Zip transcriptional factors in the potato defense response (Zanetti et al., 2004). Further, the characterization of other StMBF1 partners will allow us to understand its biological function.

MBF1 genes have been implicated in oxidative stress responses in different organisms (Jindra et al., 2004; Tsuda
(A)

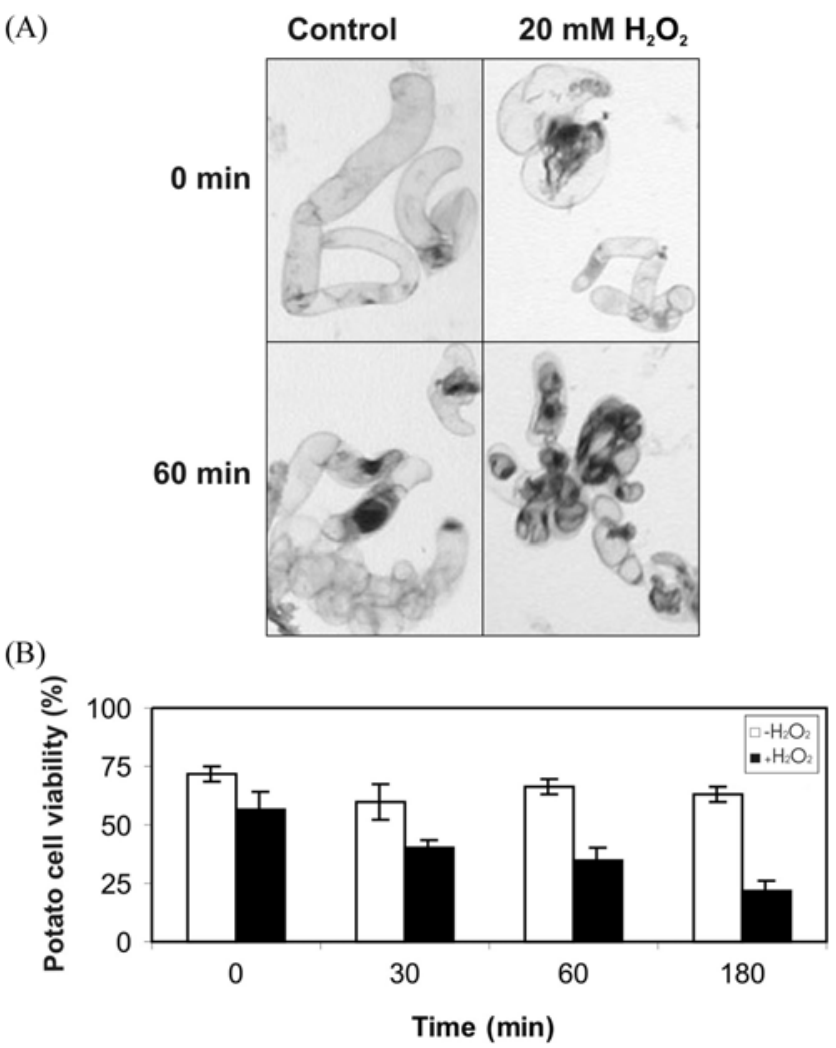

(B)

Fig. 3. Cell viability. (A) Light microscopy visualization of potato cells treated or not for $60 \mathrm{~min}$ with $20 \mathrm{mM} \mathrm{H}_{2} \mathrm{O}_{2}$ and evaluated by Evan's blue staining. (B) Time-dependent cell viability induced by $20 \mathrm{mM} \mathrm{H} \mathrm{H}_{2} \mathrm{O}_{2}$. Control cells (white columns), $\mathrm{H}_{2} \mathrm{O}_{2}$.treated cells (black columns). Values are the mean of at least three independent experiments. Vertical bars represent standard deviation. $100 \%$ of cell viability corresponds to the total number of cells visualized in each microscopy field.

and Yamazaki, 2004). Active oxygen species, especially $\mathrm{H}_{2} \mathrm{O}_{2}$ plays a critical role in the defense of plants. In this work, potato cell suspensions were subjected under oxidative stress conditions. First, the viability of potato cells exposed to $\mathrm{H}_{2} \mathrm{O}_{2}$ was monitored using Evan's blue staining. Evan's blue is excluded from viable cells but remains in dead cells (Yano et al., 1998). Fig. 3A shows the presence of numerous dark cells consisting of dead cell clusters at $60 \mathrm{~min}$ after $\mathrm{H}_{2} \mathrm{O}_{2}$-treatment (right lower panel). Fig. 3B shows the time-dependent cell viability (Fig. 3B, black columns). At $180 \mathrm{~min}$ the cell viability dropped to $25 \%$ compared to non-treated cells (75\%). In nontreated cultures the cell viability remained constant during the analyzed times (Fig. 3B, white columns). In addition, cells were treated with $20 \mathrm{mM} \mathrm{H} \mathrm{O}_{2}$ for 30,60 and $180 \mathrm{~min}$ and StMBF1 levels were analyzed by Western blot. Fig. 4B shows that the StMBF1 level clearly increased at all analyzed times after initial treatment, whereas the level of acidic potato $\beta-1,3-$ glucanase, StGluc, did not change by the $\mathrm{H}_{2} \mathrm{O}_{2}$ treatments. Such $\beta$-1,3-glucanase has been described as a patatin-like protein associated with the resistance to Phytophthora infestans 
(A)

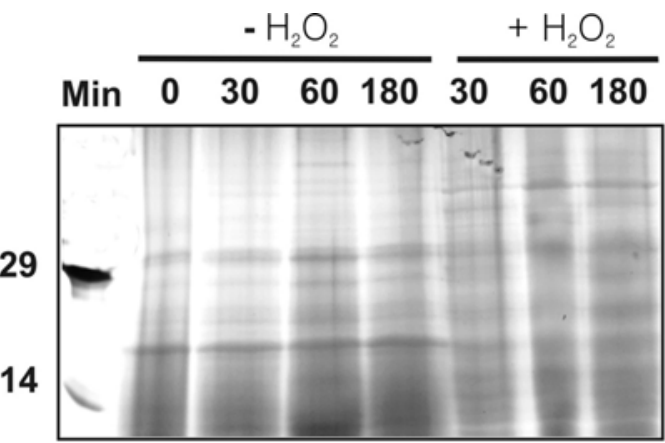

(B) StMBF1 $\min 120$

StGluc

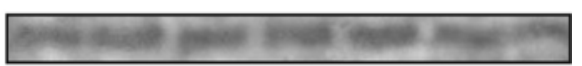

(C)

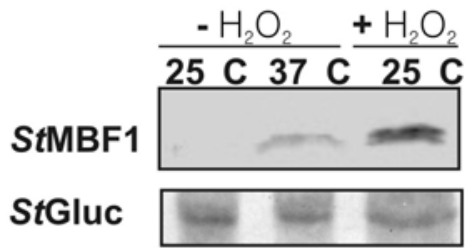

Fig. 4. StMBF1 level detected in potato cell suspensions after $\mathrm{H}_{2} \mathrm{O}_{2}$ or heat shock treatments. (A) $15 \%$ SDS-PAGE. Total protein extracts (50 $\mathrm{mg}$ fresh weight) from 4 day-old potato cell suspensions treated $\left(+\mathrm{H}_{2} \mathrm{O}_{2}\right)$ or not $\left(-\mathrm{H}_{2} \mathrm{O}_{2}\right)$ with $20 \mathrm{mM} \mathrm{H} \mathrm{H}_{2} \mathrm{O}_{2}$, were running in the gel and stained with Coomassie blue. (B) Western blot analysis using the anti-StMBF1 or the anti- $\beta-1,3-$ glucanase antibodies (upper and lower panels, respectively). (C) Potato cell suspensions were incubated for $6 \mathrm{~h}$ at $25^{\circ} \mathrm{C}$ and $37^{\circ} \mathrm{C}$ or with $20 \mathrm{mM} \mathrm{H} \mathrm{H}_{2} \mathrm{O}_{2}$ for $3 \mathrm{~h}$ at $25^{\circ} \mathrm{C}$. Western blotting was performed using the anti-StMBF1 or the anti- $\beta-1,3$-glucanase antibodies (upper and lower panels, respectively).

(Tonón et al., 2001). $\beta$-1,3-Glucanases are considered to be one component of a broad generalized defense mechanism against pathogen attack and play different biological roles in a number of plant species (Tonón et al., 2002). As control, Fig. 4A shows the loading for each sample by Coomassie blue staining. These results suggested that StMBF1 expression is strongly dependent on oxidative stress conditions. In general, organisms from prokaryotes to mammals have evolved a number of mechanisms to maintain redox balance and thus evade oxidative stress caused by naturally arising reactive oxygen species. Tsuda and Yamazaki (2004) have suggested that the AtMBF1 genes may be involved in the plant responses to multiple stresses, particularly to drought and heat shock stresses. Several reports have described that there is a link between the heat and oxidative stress responses (Banzet et al., 1998; Dat et al., 1998; Schett et al., 1999; Lee and Vierling, 2000). In our system, StMBF1 was almost undetectable in cell suspensions growing at $25^{\circ} \mathrm{C}$ (Fig. 4C, upper panel, lane 1). However, when cells were incubated for $6 \mathrm{~h}$ at $37^{\circ} \mathrm{C}$, the StMBF1 level was higher than in control cells (Fig. 4C, upper panel, lanes 2 and 1, respectively). The $\beta$-1,3-glucanase level did not increase by heat shock and $\mathrm{H}_{2} \mathrm{O}_{2}$ treatments (Fig. $4 \mathrm{C}$, lower panel). Fig. 4C, upper panel, also shows that the StMBF1 level is higher when cells are subjected to $\mathrm{H}_{2} \mathrm{O}_{2}$ than heat shock. Thus, it is reasonable to propose that $\mathrm{H}_{2} \mathrm{O}_{2}$ could be involved in the pathway of StMBF1 activation as a part of the orchestrated response of potato cells against severe oxidative stress conditions. Recently, Suzuki et al. (2005) have reported that the expression of Arabidopsis MBF1c in transgenic plants augmented the accumulation of a number of defense transcripts in response to heat stress. These results allowed us to suggest that the MBF1 genes from different plant groups (groups I and II, StMBF1 and AtMBF1 c, respectively) may share similar functions during the response against oxidative stress conditions. In addition, the data reinforce the hypothesis that MBF1 function is conserved between different plant species. Although still unclear is the role of StMBF1 in potato plants growing under environmental stresses, our findings provide fundamental bases to clarify regulatory genes involved in the potato defense mechanisms. It is an important subject in the agronomical field since potato represents the fourth horticole species in the world and its crop is strongly affected by biotic and abiotic stresses.

Acknowledgments This research was supported by grants from the IFS, Sweden, UNMDP, CONICET, ANPCyT, Argentina. CC and AG are members of CONICET. DA is a fellow of the same Institution. The authors wish to thank Dr Kenichi Tsuda and Dr Ramiro París for their helpful assistance and Dr Flavio Blanco for the potato cell suspensions.

\section{References}

Banzet, N., Richaud, C., Deveraux, Y., Kazmier, M. and Gagnon, J. (1998) Accumulation of small heat shock proteins, including mitochondrial HSP22, induced by oxidative stress and adaptative response in tomato cells. Plant J. 13, 519-527.

Brendel, C., Gelman, L. and Auwerx, J. (2002) Multiprotein bridging factor-1 (MBF-1) is a cofactor for nuclear receptors that regulate lipid metabolism. Mol. Endocrinol. 16, 1367-1377.

Busk, P., Wulf-Andersen, L., Strom, C., Enevoldsen, M., Thirstrup, K., Haunso, S. and Sheikh, S. (2003) Multiprotein bridging factor 1 cooperates with c-jun and is neccesary for cardiac hypertrophy in vitro. Exp. Cell. Res. 286, 102-114.

Dat, J. F., Foyer, C. H. and Scott, I. M. (1998) Changes in salicylic acid and antioxidants during induced thermotolerance in mustard seedlings. Plant Physiol. 118, 1455-1461.

Godoy, A.V., Zanetti, M. E., San Segundo, B., Casalongué, C. A. (2001) Identification of a putative Solanum tuberosum transcriptional coactivator up-regulated in potato tubers by Fusarium solani f. sp. eumartii infection and wounding. Physiol. Plant. 112, 217-222.

Harlow, E. and Lane D. (1988) Antibodies. A laboratory manual. Cold Spring Harbor, Cold Spring Harbor Laboratory Press, USA.

Jindra, M.G. I., Uhlirova, M., Okabe, M., Hiromi, Y. and Hirose, S. (2004) Coactivator MBF1 preserves the redox-dependent 
AP-1 activity during oxidative stress in Drosophila. EMBO. J. 23, 3538-3547.

Kabe, Y., Goto, M., Shima, D., Imai, T., Wada, T., Morohashi, K., Shirakawa, M., Hirose, S. and Handa, H. (1999) The role of human MBF1 as a transcriptional coactivator. J. Biol. Chem. 274, 34196-34202.

Lee, G. H. and Vierling, E. (2000) A small heat shock protein cooperates with heat shock protein 70 systems to reactivate a heat-denatures protein. FASEB J. 13, 833-842.

Li, F. Q., Ueda, H. and Hirose, S. (1994) Mediators of activation of fushi tarazu gene transcription by BmFTZ-F1. Mol. Cell. Biol. 14, 3013-3021.

Murashige, T. and Skoog, F. (1962) A revised medium for rapid growth and bioassays with tobacco tissues cultures. Physiol. Plant. 15, 473-497.

Pugh, B. F. (2000) Control of gene expression through regulation of the TATA-binding protein. Gene 255, 1-14.

Schett, G., Steiner, C. W., Groger, M., Winkler, S., Graninger, W., Smolen, J., Xu, Q. and Steiner, G. (1999) Activation of Fas inhibits heat induced activation of HSF1 and up-regulation of HSP70. FASEB J. 13, 833-842.

Suzuki, N., Rizhsky, L., Liang, H., Shuman, J., Shulaev, V. and Mittler, R. (2005) Enhanced tolerance to environmental stress in transgenic plants expressing the transcriptional coactivator multiprotein bridging factor 1c. Plant Physiol. 139, 1313-1322.

Swaffield, J. C. and Johnston, S. A. (1996) Affinity purification of proteins binding to GST fusion proteins. Curr. Prot. Mol. Biol. John Wiley and Sons, Inc., USA.

Takemaru, K., Harashima, S., Ueda, H. and Hirose, S. (1998) Yeast coactivator MBF1 mediates GCN4-dependent transcriptional activation. Mol. Cell. Biol. 18, 4971-4976.

Takemaru, K., Li, F. Q., Ueda, H. and Hirose, S. (1997) Multiprotein bridging factor 1 (MBF1) is an evolutionarily conserved transcriptional coactivator that connects a regulatory factor and TATA element-binding protein. Proc. Natl. Acad.
Sci. USA 94, 7251-7256.

Tonón, C., Daleo, G. and Oliva, O. (2001) An acidic b-1,3 glucanase from potato tubers appears to be patatin. Plant Physiol. Biochem. 39, 849-854.

Tonón, C., Guevara, G., Oliva, C. and Daleo, G. (2002) Isolation of a potato acidic $39 \mathrm{kDa}$ b-1,3 glucanase with antifungal activity against Phytophthora infestans and analysis of its expression in potato cultivars differing in their degrees of field resistance. J. Phytopatol. 150, 189-195.

Tsuda, K., Tsuji, T., Hirose, S. and Yamazaki, K. (2004) Three Arabidopsis MBF1 homologs with distinct expression profiles play roles as transcriptional co-activators. Plant Cell Physiol. 45, 225-231.

Tsuda, K. and Yamazaki, K. (2004) Structure and expression analysis of three subtypes of Arabidopsis MBF1 genes. Biochim. Biophys. Acta 1680, 1-10.

Yano, A., Suzuki K., Uchimiya, H. and Shinshi, H. (1998) Induction of Hypersensitive Cell Death by a Fungal Protein in Cultures of Tobacco Cells. Mol. Plant Microbe Interaction 11, 115-123.

Zanetti, M. E., Blanco, F. A., Daleo, G. R. and Casalongue, C. A (2003) Phosphorylation of a member of the MBF1 transcriptional co-activator family, StMBF1, is stimulated in potato cell suspensions upon fungal elicitor challenge. J. Exp. Bot. 54, 623-632.

Zanetti, M. E., Chan, R. L., Godoy, A. V., Gonzalez, D. H. and Casalongué, C. A. (2004) Homeodomain-leucine zipper proteins interact with a plant homologue of the transcriptional co-activator multiprotein bridging factor 1. J. Biochem. Mol. Biol. 37, 320-324.

Zhu, G., La Gier, M. J., Hirose, S. and Keithly, J. S. (2000) Cryptosporidium parvum: functional complementation of a parasite transcriptional coactivator CpMBF1 in yeast. Exp. Parasitol. 96, 195-201. 